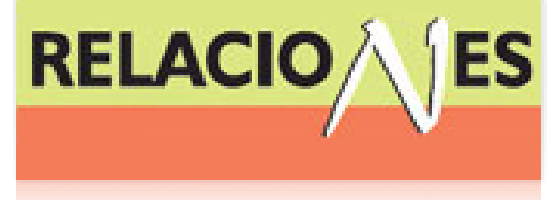

Relaciones. Estudios de historia y sociedad ISSN: 0185-3929

relacion@colmich.edu.mx

El Colegio de Michoacán, A.C

México

González Pérez, Damián

Introducción del café en Oaxaca según documentos del Archivo del Poder Ejecutivo del Estado: el caso de Santiago Xanica

Relaciones. Estudios de historia y sociedad, vol. XXXIII, núm. 130, 2012, pp. 131-154

El Colegio de Michoacán, A.C

Zamora, México

Disponible en: http://www.redalyc.org/articulo.oa?id=13723093006

- Cómo citar el artículo

- Número completo

- Más información del artículo

- Página de la revista en redalyc.org

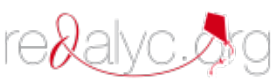

Sistema de Información Científica

Red de Revistas Científicas de América Latina, el Caribe, España y Portugal Proyecto académico sin fines de lucro, desarrollado bajo la iniciativa de acceso abierto 


\title{
Introducción del café en Oaxaca según documentos del Archivo del Poder Ejecutivo del Estado: el caso de Santiago Xanica
}

\author{
Damián González Pérez* \\ UNIVERSIDAD NACIONAL AUTÓNOMA DE MÉXICO
}

PreÁmbulo: UnA historia de CAFÉ ${ }^{\mathrm{I}}$

En la segunda mitad del siglo xIx, Oaxaca vivió un proceso de sustitución e implantación económica importante, derivado de la crisis de la grana cochinilla, producto que durante buena parte del periodo colonial fue la segunda actividad más rentable en la Nueva España, sólo por detrás de la minería. Fue el área del sur, en particular la alcaldía mayor de Miahuatlán, la zona de donde se obtenía uno de los tintes de mejor calidad. ${ }^{2}$ El monocultivo de la grana cochinilla impactó de manera severa la producción de alimentos básicos, al grado que varias comunidades de dicha región debían adquirir el maíz en la cabecera de Miahuatlán o por medio de los repartimientos. Algunos documentos del Archivo General de la Nación (AGN) dan cuenta de los problemas comerciales que desde finales del siglo xviıI comenzó a tener este mercado y las medidas adoptadas por el alcalde mayor de Miahuatlán para tratar de revertirlo. ${ }^{3}$

\footnotetext{
*tlet1313@hotmail.com

${ }^{1}$ Una primera versión del texto, así como de algunos de los documentos presentados a continuación, aparece en mi Tesis de Maestría con el subtítulo "La encrucijada del café: una historia reciente, pero añeja": Damián González Pérez, Las huellas de la culebra. Historia, mito y ritualidad en el proceso fundacional de Santiago Xanica, Oaxaca, Tesis de Maestría en Antropología, México, unam, Facultad de Filosofía y Letras e Instituto de Investigaciones Antropológicas, 2010, 77-81, 195-200.

${ }^{2}$ Joseph W. Whitecotton, Los zapotecos: príncipes, sacerdotes y campesinos, México, Fondo de Cultura Económica, 1985, 222.

${ }^{3}$ AGN, Industria y Comercio, vol. 9, exp. 4, 1778; AGN, Industria y Comercio, vol. 9, exp. 9, 1979; Tributos, vol. 14, exp. 23, 1780.
} 
El decaimiento del mercado de la grana dio paso a la introducción del café, que se convirtió en poco tiempo en el nuevo medio de explotación de comunidades zapotecas, chatinas, chontales y mixes del sur y la costa. Basilio Rojas Mijangos, político y escritor miahuateco, describe a su manera la forma en que fue introducido el grano en esta zona, y en Oaxaca en general. ${ }^{4}$ Fueron precisamente los antiguos comerciantes y acaparadores (terratenientes) de grana de Miahuatlán quienes buscaron contrarrestar esta crisis. Según el autor, fue en la localidad de San Isidro del Camino donde, entre 1873 y 1874 , se sembraron las primeras matas del grano, en terrenos del pueblo de San Isidro del Camino, junto al "camino nacional" que desde entonces conectaba a Miahuatlán con Pochutla. Sin embargo, inicialmente hubo oposición por parte de los habitantes de dicha comunidad, así como de las autoridades del partido de Pochutla, por tanto:

Los excursionistas (un grupo de 7 accionistas quienes se habían constituido legalmente como sociedad) decidieron establecerse en un lugar cercano a San Isidro, pero donde los indios de este pueblo no pudieran alegar derecho alguno así es que una mańana temprano, sin decir a donde se encaminaban salieron de aquel pueblo y haciendo que volvían a Miahuatlán tomaron el rumbo de Huatulco y fueron a establecerse en el Cerro de la Pluma y dando al sitio elegido por nombre el de LA PROVIDENCIA. ${ }^{5}$

Con la finalidad de apoderarse "legalmente" del terreno conocido como Cerro de la Pluma, las autoridades de Miahuatlán buscaron el apoyo del entonces gobernador de Oaxaca para que los municipios de Santa María Ozolotepec y San Mateo Río Hondo cedieran una parte de sus terrenos. De esta manera, el $1^{\circ}$ de diciembre de 1880 se creó por decreto del gobierno del estado el pueblo de Pluma Hidalgo. ${ }^{6}$

\footnotetext{
${ }^{4}$ Basilio Rojas, El café. Estudio de su llegada, implantación y desarrollo en el estado de Oaxaca, México, México, Sociedad Mexicana de Geografía e Historia, 1964.

${ }^{5}$ Ibidem, p. 53.

${ }^{6}$ Ibidem, pp. 54, 57.
} 
No hubo una sola familia de Miahuatlán que no tuviera cuando menos uno de sus miembros o un deudo metido en aquella nueva empresa. No parecía que se trataba de realizar un esfuerzo máximo y totalmente distinto de los usos labrantíos del pueblo de origen, sino una romería hacia un sitio consagrado, un viaje de placer o un paseo sencillo, del que se podían volver fácilmente con las faltriqueras llenas como si se tratara de una Jauja, de un Potosí o de acudir a unos grandes placeres argentíferos. Y así los ricos iban para tomar posiciones para acrecentar sus riquezas; los pobres para hacerse de un sitio donde sus esperanzas dejaran de ser sueños irrealizados... ${ }^{7}$

El segundo experimento de introducción del café se llevó a cabo en 1875 y tuvo lugar en Santo Domingo Coatlán. Fue precisamente Basilio José Rojas Bustamante, antiguo comerciante y acaparador de grana cochinilla, y abuelo de Basilio Rojas, quien se encargó de establecer una nueva finca. Al principio, Rojas se enfrentó a la "reticencia idiosincrática del indio", por lo que tuvo que esperar a que se realizara una asamblea general en la que se discutiera su solicitud para adquirir un terreno dentro de los límites del pueblo. Como condición, las personas del pueblo exigieron a Rojas que se estableciera en la comunidad como un "contribuyente" más, adquiriendo de esta manera los mismos derechos y obligaciones que el resto de la gente. Finalmente fue un hijo de nombre Vidal quien se quedaría allí para fundar la segunda finca de café en el estado llamada Regadío.

Para 1877, tocó el turno al pueblo de Santiago Xanica sufrir el proceso de implantación del cultivo del café. ${ }^{8} \mathrm{Al}$ respecto, Rojas señala que los encargados de hacerlo fueron dos hermanos de nombre Pedro y Teófilo Díaz:

Don Pedro Díaz había sido agricultor del sitio de Xitlapehua, a quien le había tocado resentir los efectos de la baja de la grana [...] Era hermano de don Teófilo, un trotamundos muy conocedor de los terrenos de Huatulco,

${ }^{7}$ Ibidem, p. 56.

${ }^{8}$ Según un reporte de Manuel Martínez Gracida, diez años antes aún no se cultivaba café en Xanica: Biblioteca Genaro V. Vásquez, Colección Manuel Martínez Gracida, Documentos para la geografia y toponimia de Oaxaca, vol. 53, 1866, f. 377r. 

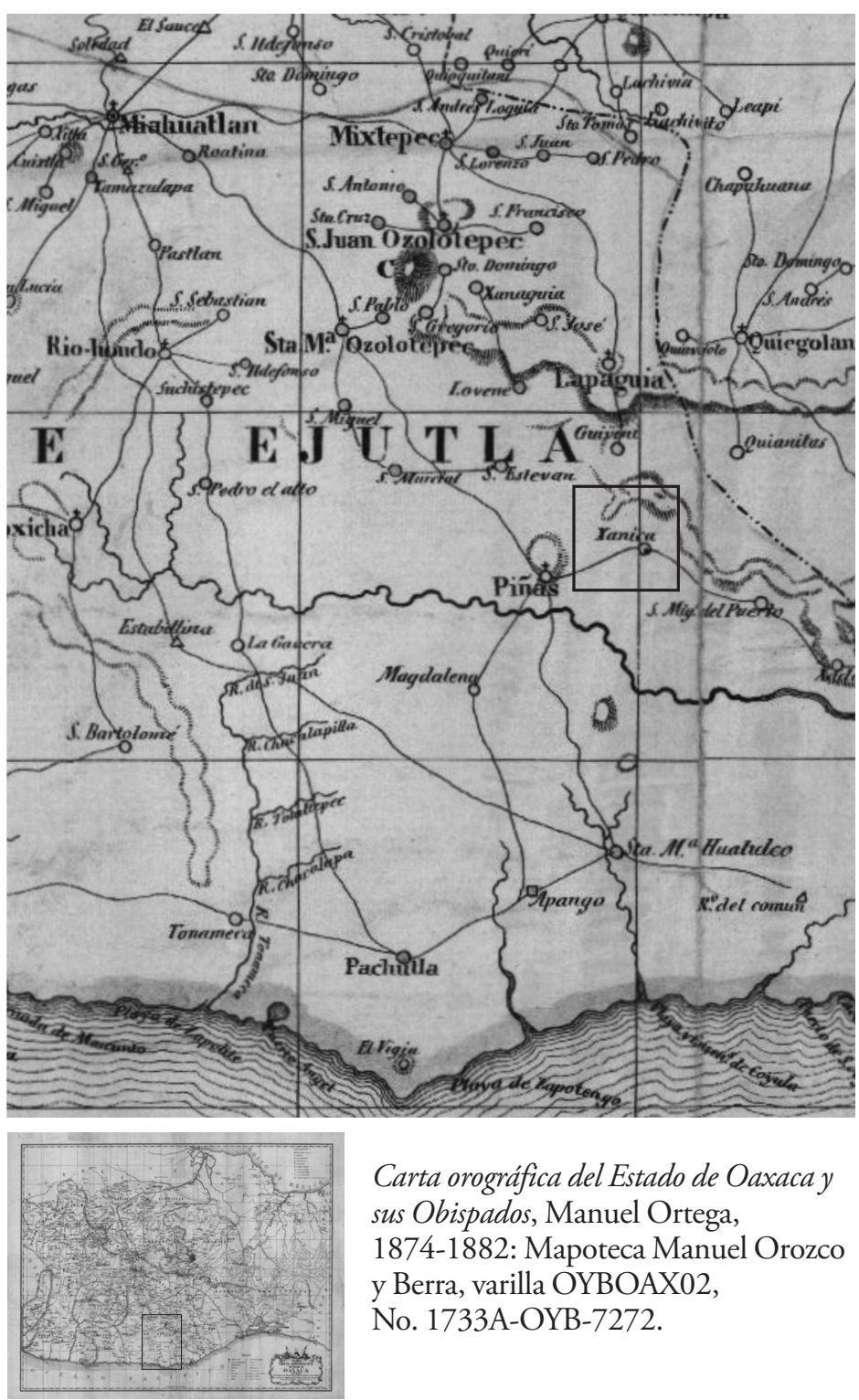

Carta orográfica del Estado de Oaxaca y sus Obispados, Manuel Ortega,

1874-1882: Mapoteca Manuel Orozco y Berra, varilla OYBOAX02,

No. 1733A-OYB-7272. 
Tehuantepec y Pochutla, por donde transitaba arriando ganado que por allá compraba, o llevando recuas de mulas con algún cargamento, por lo cual cuando se trató de que el café requería un clima determinado, aquel individuo señaló a su hermano como lugar propicio las faldas del cerro de la Sirena en la parte correspondiente al pueblo de Xanica [...] Para ese sitio se fue don Pedro y allí fundó "La Sirena", una de las fincas más hermosas del Estado y la que, según el decir de algunos expertos, produce el mejor café de la entidad. ${ }^{?}$

$\mathrm{Al}$ igual que en otros casos, el estatus político y administrativo de Xanica estuvo sujeto a los intereses de comerciantes y finqueros, así como de los gobiernos regional y estatal. En otro lugar, Rojas explica dicha situación:

Este pueblo formó parte de la jurisdicción del Distrito de Pochutla, hasta el 5 de diciembre de 1877, en que por decreto del Gobierno del Estado, pasó a depender del de Miahuatlán. Condiciones geográficas y circunstancias políticas determinaron este cambio; las primeras, por la mejor facilidad de comunicación que tiene Xanica con Miahuatlán que con Pochutla; y las segundas porque el distrito de Miahuatlán apoyaba más fuertemente la implantación del cultivo del café, que entonces se iniciaba, impulsando y alentando a los posibles cafeticultores, para lo cual era conveniente que un pueblo como Xanica, que contaba con buenos terrenos para café dependiera mejor de Miahuatlán que de Pochutla, donde no había por entonces entusiasmo para este cultivo. ${ }^{10}$

En su papel de político e influyente, descendiente de una familia que se había dedicado primero a la comercialización de la grana cochinilla y después al café, Basilio Rojas justifica la creación de la finca La Sirena, junto con otra colindante llamada El Gavilán, gracias a la supuesta apertura y "buena voluntad" de los habitantes de Xanica:

${ }^{9}$ Rojas, 1964, op. cit., p. 64.

${ }^{10}$ Basilio Rojas, Miahuatlán, un pueblo de México. Monografia del Distrito de Miahuatlán, estado de Oaxaca, t. I, Oaxaca, México, Gráfica Cervantina, 1958, 425. 
La fundación de las fincas cafetaleras de "El Gavilán" y "La Sirena" se debió en mucha parte a la buena acogida que tuvieron los iniciadores de aquellas empresas, de parte de las autoridades y vecinos de Xanica, quienes recibieron a los interesados con simpatía y los trataron con amabilidad, dándoles toda clase de facilidades. Esa meritoria conducta debe tomarse muy en cuenta en favor de Xanica, pues sin egoísmos de ninguna especie, dejó que gente de mayores recursos económicos e intelectuales se estableciera en la región, mediante un convenio tácito de mutuo respeto y consideración. ${ }^{11}$

En la memoria de algunos abuelos del pueblo aún se conserva el recuerdo de Pedro Díaz como la persona que llevó el café a Xanica:

El café empezó hace unos 150 años. Eso sí me contaba muy bien mi abuelito, porque él tenía mucha gente superior, gente más antigua. Le contaban que el café viene de Pluma. Un señor que vino acá y lo nombraron como secretario, un Pedro Díaz (él ha de ser de Miahuatlán). Él estuvo aquí como secretario y tuvo un compadre que vivió aquí en el río San Jerónimo, ahí vivió el señor. Ya luego fue a traer el café de Pluma, fue a traer el almácigo y ya cuando estuvo así chiquito empezó a repartir las plantitas a la gente. ${ }^{12}$

\section{SOBRE LOS DOCUMENTOS}

A continuación se presenta una serie de documentos que forman parte de dos expedientes localizados en el Archivo del Poder Ejecutivo del Estado de Oaxaca (APEO), cuyo contenido refiere precisamente a la apertura de la finca La Sirena, localizada dentro del territorio del pueblo de Santiago Xanica. A lo largo de los documentos se puede observar el procedimiento que los antiguos comerciantes de grana cochinilla emplearon en varias comunidades para sustituir dicho cultivo por el del café. De esta manera, es posible tener una perspectiva distinta sobre este proceso, en el que fue fundamental el apoyo que las autoridades políticas regionales y estatales dieron a comerciantes y empresarios, tal como se vio líneas arriba.

${ }^{11}$ Ibidem.

${ }^{12}$ Señor Gregorio Cruz Aquino, Santiago Xanica, abril de 2009. 
Un aspecto que debe tomarse en cuenta al momento de revisar los documentos es que el terreno de Xanica, cuyo tipo de propiedad era comunal hasta principios del siglo xx, para la década de los treinta de ese siglo se convirtió en propiedad privada, lo que impactó severamente la organización social y política, así como la producción de alimentos básicos, la cual había decrecido con anterioridad, debido a la especialización en la producción de grana cochinilla.

$\mathrm{Al}$ igual que en otras regiones de Oaxaca, la instalación de fincas cafetaleras, pero sobre todo la conversión de la actividad agrícola y económica del pueblo hacia el monocultivo del café, trajo consigo un incremento en la violencia interna, la cual se vio reflejada en cada vez mayor polarización y división, dando como resultado un enfrentamiento entre los años 1951 y 1952. Dicho suceso trajo consigo la muerte de al menos 40 personas. Las versiones en torno a este acontecimiento, denominado "la guerra del 52", son diversas y siguen marcando la relación entre algunas de las familias del pueblo.

Los documentos que ahora se presentan permiten acercarse de alguna manera a una historia relativamente común en comunidades zapotecas, chatinas, mixes y chontales del sur de Oaxaca. La selección de los textos de los dos expedientes se hizo con la finalidad de lograr una lectura fluida, pero que permitiera dar seguimiento al desarrollo del caso que se presenta, que es, como ya se dijo, la introducción del café en la comunidad y la apertura de la finca La Sirena.

DoCUMENTOS DEL PRIMER EXPEDIENTE

Gobierno de los distritos, Miahuatlán, leg. 21, exp. 26, 1890

Pide que se repriman los abusos cometidos por el Presidente Municipal de Xanica contra sus propiedades y que le repare o le indemnice los perjuicios que le ha causado

\section{Gobernador}

Pedro Díaz, vecino de Xitlapehua del Distrito de Miahuatlán ante Ud. como mejor lugar haya en derecho y con el más alto respeto, 
expongo que desde el año de mil ochocientos ochenta me adjudiqué en propiedad y conforme a la ley de 25 de junio de 1856 un terreno montuoso ubicado en términos del pueblo de Xanica del mismo Distrito, en precio de doscientos pesos que me obligué á pagar al vencimiento de diez años, con el rédito estipulado de $6 \%$ al año. Desde que me hice dueño del terreno comencé á desmontarlo y abrirlo al cultivo, estableciendo mi casa y un plantío de café compuesto de quince mil cafetos. Antes del vencimiento del plazo de la escritura de venta intenté hacer al Municipio de Xanica algunos pagos ya por cuenta del capital, y ya por réditos vencidos, pero no hallé buena disposición por parte del representante del pueblo para recibir ninguna cantidad de dinero; por esto al principio de este año que es en el que se cumple el plazo para pagar el precio del terreno y los réditos vencidos consigné al Juzgado de $1^{a}$ Instancia de Miahuatlán la cantidad de trescientos veinte pesos que reportan el precio y los réditos, y quedé conforme á la ley que se citara al representante de Xanica á recibir la cantidad consignada en pago y en caso de oposición se depositara jurídicamente el dinero.

La cuestión perjudicial sigue en curso con la lentitud con que se administra la justicia, como Ud. muy bien lo sabe, y si no adjunto á este recurso el título de mi propiedad, que es en el que fundo esta queja, es por que la tengo presentada en los autos de consignación. Pero el medio que he adjuntado para ampliar mi obligación, á pesar de ser ajustado á la ley, ha dado motivo para que las autoridades de Xanica hayan mandado cometer una serie de abusos contra las personas de mis dependientes que cuidan y trabajan en mi finca de La Cirena y contra mi propiedad y posesiones. Por los oficios que adjunto en 3 fojas útiles se designará $\mathrm{Ud}$. ver que desde el 12 de junio próximo pasado el Presidente $\mathrm{Mu}-$ nicipal de Xanica comenzó á exigir a mis mozos que se retiraran de mi finca, amagandolos y amenazandolos con que los sacarian y destruirían mis casas y plantaciones, y el [auxilio] de hombres con que [...] ofició de 29 de junio cumplió las órdenes de su presidente, fines sacó á mi casa á Justo Cortes que es el encargado de mi finca y a su familia y destruyó dos casas, la que está situada en el río en donde tengo los almácigos de cafetos y la que está en el cafe- 
tal de la montaña y de donde se llevaron mas de cien matas en estado de producto.

Estos hechos, Señor Gobernador, son un atentado contra la propiedad, y lo que es mas grave todavía, un indicio claro de desmoralización administrativa. Cuando se vé que el encargado por la ley para asegurar las personas y los intereses de los ciudadanos es el primero en vulnerarlas, fallarlas y destruirlas, ¿Quién ha de lanzarse a los campos, en el centro de nuestras grandes montañas, á desenajenar la tierra y disponerla á las empresas agrícolas, si en un momento dado se espera ser destruidos por una mano bárbara, sus trabajos de muchos años, y con esto sus riquezas y el porvenir de todo? El buen nombre de la administración de Ud. C. Gobernador, los intereses generales de la sociedad que Ud. tan sabiamente gobierna, y el celo y actividad desplegados en estos últimos ańos por el Gobierno de la Nación para que los trabajos y posesiones rurales gocen de toda la protección que las leyes de la patria les conceden, exigen que se reformen los abusos cometidos en las personas de mis operarios y de mis propiedades.

No acuso criminalmente al Municipio de Xanica porque en las agitaciones del despacho [...], cuando en lugar de escribir et. se escribe B. de mala fé, la mas santa de las causas se desvirtúa y el acusador sobre la [...] y el ridículo, se atrae el encono y el odio de los acusados. Yo solo pido, Señor, que en la via gubernativa se le prevenga al Presidente Municipal de Xanica por conducto del Jefe político del Distrito de Miahuatlan que cese de cometer la serie de abusos y atropellamientos que está llevando á cabo contra las personas de mi dependientes y contra mi propiedad, que respete mis trabajos y plantaciones [...] en el terreno de La Cirena que repare ó me indemnice de los prejuicios que me ha causado; y que si algún derecho cree tener en el terreno expresado que lo haga valer ante las autoridades competentes, cuyo fallo protesto acatar debidamente. Por tanto,

A Usted suplico se sirva acordar de conformidad. Protesto no proceder de malicia y lo firmo.

Miahuatlan, Julio cuatro de mil ochocientos noventa

Pedro Díaz 


\section{$[\ldots]$}

Al margen una estampilla de á cincuenta centavos debidamente cancelada:

Miahuatlan Mayo veintitrés de mil ochocientos noventa.- Por presentado en la fecha con la credencial que se acompaña como lo pide previa citación del C. Pedro Diaz y del representante del Ministerio público. El C. Lic. Efraín Rojas Juez de primera instancia del Distrito así lo proveyó y firmó doy fé.- Efraín Fojas- Julio López Srio.- C. Juez de $1^{\mathrm{a}}$ instancia: Antonio Andrés Síndico procurador del pueblo de Santiago Xanica de este Distrito como se comprueba con la credencial que en una foja útil debidamente acompaño y de la que toma la razón pido me sea devuelta ante $\mathrm{U}$. como proceda mejor en derecho respetuosamente comparezco y digo que en el año de mil ochocientos ochenta otorgó el municipio de mi representado escritura pública á los Señores Teofilo y Pedro Díaz sobre venta de un terreno á curso reservativo redimible y con necesidad del testimonio de la escritura á que hago referencia acudo á U. suplicándole se sirva espedirmelo en los términos prevenidos por el artículo sesenta y tres del Código de procedimientos civiles vigente con citación del referido Pedro Díaz y del Ministerio público. Mi pedido se funda en justicia y A U. suplico provea como solicito Protesto con lo necesario $=$ Miahuatlan Mayo 22 de $1890=$ Antonio Andrés $=\mathrm{Al}$ margen una estampilla de á cincuenta centavos debidamente cancelada. $=\mathrm{Al}$ margen un sello que dice: Municipio de Santiago Xanica. Distrito de Miahuatlan $=[\ldots]$ En el pueblo de Santiago Xanica á los veinticuatro días del mes de enero de mil ocho cientos ochenta, Reunido el Ayuntamiento en su sala de consejo bajo la presencia del Ciudadano Manuel Gonzalez el Síndico ciud[adano] Pedro Nolasco en [...] de la palabra dijo: que al poniente de la población se encuentra un sitio que colinda por el Oriente por toda la corriente del río del pueblo viejo de $[\mathrm{H}]$ uistepec por el Poniente con la Cruz que le llaman del mojón que divide tierras del pueblo con las de San Juan Ozolotepec y Santa María Ozolotepec, siguiendo la línea actual Sur hasta el paraje cruz de las águilas de aquí á la del tecolote desde aquí comienza la colindancia con Piñas, de este paraje al de Buenavista y 
de aquí por toda una loma con inclinación al Sur Este hasta juntarse con la línea formando una lengua por el Sur y por el Norte San Andres Lovene desde el paraje "colorado" por todo el camino viejo que se junta con el de dicho pueblo, y estando este ocupado hace mas de tres años por los Ciudadanos Pedro Díaz y Teofilo Diaz sin que le redime al Ayuntamiento cosa alguna, que bien pudiera servirle a éste para sus presisos gastos, propone el Ayuntamiento el que el referido sitio, se venda al mismo Señor si otro cualquiera si les conviene en la cantidad de doscientos pesos por lo menos a plazo y con el rédito de seis por ciento anual mientras no se paga el precio lo que [...] por el Ayuntamiento aprobó la proposición por unanimidad y acordándose la expedición de la copia de este acuerdo al Síndico para que se presente en el Juzgado del Distrito á otorgar la escritura respectiva se dió por terminado el acto levantándose la presente, que discutida y aprobada la firmaron los que supieron y por los que no saben firmar el Secretario municipal = Esteban López, Srio. - Es copia fiel de su original que certifico Santiago Xanica, Enero 24 de 1880 = Por el C. Manuel González, presidente municipal y Síndico Pedro Nolasco que no saben y los Regidores ciudadanos Julian José López, Cresencio Marcelino, Francisco Lorenzo y Juan García, que no saben escribir. $=$ Esteban López, Srio., concertada la venta a plazo de un sitio al poniente del pueblo de Santiago Xanica mismo que comprendido en la demarcación del pueblo citado que representa el primero de los otorgantes; el segundo con su hermano lo há poseído y poseé en arrendamiento hace mas de tres años el cual colinda como queda especificado en el acuerdo exhibido. Y para llevar á efecto dicho convenio en la via y forma que mas haya lugar en derecho, el referido Pedro Nolasco á [...] del común que representa, Otorga: que dá en venta á plazo al C. Pedro Díaz el mencionado sitio que declaran no está libre de toda responsabilidad y gravamen por lo que como tal lo vende con todas sus entradas y salidas, usos y servidumbres u demás cosas anexas que tenga y de derecho le correspondan por la cantidad de doscientos pesos que es su justo precio y mediante á un parecer de presente sin habérsele satisfecho antes de [...] dicha cantidad queda reservada sobre el sitado sitio con obligación de pagar al Ayuntamiento de Santiago Xanica la pension de 
doce pero al respecto de seis por ciento anual en la casa de comunidad de aquel el dia diez de Febrero de cada año en buenas y concientes maneras libres de todo descuento de impuestos de toda clase sobre capital y réditos mientras no se redima el capital que el citado Señor Díaz se obliga á hacerlo en termino de diez años contados desde la fecha, haciéndolo integro; pues no se le administran entregas parciales, reservándose el Ayuntamiento como lo reserva en nombre de aquel el beneficio que le artículo tres mil doscientos diez y ocho del Codigo civil le concede para los casos en el previstos de quiebra ó de insolvencia del comprador o falta de pago de una sola de las pensiones en cuyo caso será exigible el capital antes del plazo prefijado en este contrato, con mas los daños y prejuicios y pago de los gastos judiciales con arreglo á los artículos mil quinientos treinta y siete, mil quinientos treinta y cinco y mil quinientos noventa y nueve del citado código civil á cuyo efecto manifiesta que el sitio deslindado queda hipotecado y por tanto de conformidad al artículo mil novecientos cuarenta y uno sujeto a responder al capital, réditos y demás que reza esta escritura y con la prelación que acuerdan las disposiciones de la materia. El Señor Don Pedro Diaz dijo: que acepta esta escritura en todas sus partes y en consecuencia se obliga a los preceptos que en ella se contiene renunciando expresamente el beneficio que concede el artículo mil treinta y nueve del Código de procedimientos, pues llegado el caso en el previsto se obliga á pagar las costas aunque satisfaga y haga la redención antes de las veinticuatro horas siguientes al requerimiento. Y yo el juez receptor advertí a los otorgantes la obligación, según el artículo dos mil diez y siete del Código civil de registrar esta escritura por la hipoteca que contiene en el registro público del Distrito y que con este requisito llenado dentro de los primeros seis días producirá sus efectos contra tercero desde la fecha de esta escritura con arreglo al artículo tres mil trescientos cincuenta y tres, pero pasado ese término sin que sea registrada surtirá sus efectos tan solamente desde la fecha de su inscripción según la presentación de este mismo artículo y leida que les fue á los otorgantes ante los testigos instrumentales imponiéndoles al propio tiempo de lo que disponen los artículos citados, conformes con su tenor quedaron enterados á su satisfacción del valor y 
fuerza de las clausulas que contiene. Así lo otorgaron siendo testigos los CC. Efrén Rojas y Lic. Rafael Parra de esta vecindad y mayores de edad y firmaron haciéndolo por el rendador que dijo no saberlo hacer su Secretario con el suscrito Juez damos Fé. = Miguel R. Meijueiro $=$ Pedro Díaz. $=$ Por el Síndico Pedro Nolasco que no sabe escribir, Esteban López, S[ecretario] = R. Parra. = Efraín Rojas = H. F. Vera. $=$ D.A. Fran[cisco]. Zurita $=$ Julio López, Srio.

$==\mathrm{EP} .=$ nueve $=$ se encuentra $=$ No vale

Se recibió en esta Jefatura el recurso presentado á esa Superioridad por el C. Pedro Díaz, que me remite con su comunicación fecha 8 del actual. Ya se pide al Presidente m[unici]pal de Xanica el informe respectivo para los efectos del acuerdo superior que le recayó.

Libertad y Constitución

Miahuatlan Julio 12 de 1890

El Jefe político

Feliciano García

Al C. Srio. Del Despacho del Superior

Gobierno del Estado

Oaxaca de JZ

\section{$[\ldots]$}

Pide se decida en el expediente formado

á virtud de su queja sobre desmanes, vejaciones y destrucción de casas por el presidente de Xanica el veintinueve de

junio último

\section{Gobernador}

Pedro Diaz, en el expediente administrativo formado en virtud de mi queja sobre desmanes, vejaciones y destrucción de casas cometidos por el presidente de Xanica de este Distrito, en mi finca denominada "La Sirena" ante Ud. en la mejor forma de derecho y con el mas alto respeto expongo: que hace treinta y ocho diaz que por superior acuerdo se remitió el espediente al Jefe Político para que informara sobre los hechos denunciados con justificación; y como la 
relación en resolver sobre mi queja me perjudica notablemente porque no puedo atender al cultivo y veneficio del cafetal, habiendo perdido yá el tiempo oportuno en la presente estación de aguas para el trasplante de cafetos y perjudica al Estado porque la impunidad de tales hechos disminuye la garantía de seguridad de los industriales cafeteros, vengo a agitar el curso de ese espediente y á suplicar á Ud. se sirva acordar se le dé cuenta con él para decidir de mi queja. Por tanto

A Ud. suplico se sirva decretar de conformidad.

Miahuatlan Agosto diez y ciete de mil ochocientos noventa Pedro Diaz

$$
[\ldots]
$$

Ciudadano Jefe Político

El que suscribe Presidente Municipal de Santiago Xanica, cumpliendo en lo que le corresponde con lo mandado en la Superior determinación que recayó al ocaso que precede voy a exponer ante Ud. para sus efectos y por vía de informe lo siguiente. No es cierto que el acusante Pedro Díaz se haya adjudicado como asegura fracción alguna de terreno perteneciente a mi pueblo; conforme á la ley de 25 de Junio de 56: el contrato al que seguramente quiso referirse $\mathrm{y}$ tan maliciosamente pretende revertir con las formalidades de la ley que cita consta en el testimonio adjunto, y acerca de su validez ya nos ocupamos ante la autoridad que al caso corresponde. No es cierto que el mismo Señor Díaz alguna vez haya pretendido hacer pago alguno al Municipio de mi pueblo por razón del contrato aludido y así consta en los autos que se siguen en el Juzgado de $1^{\mathrm{a}}$ instancia de este Distrito y que él promovió haciendo consignación de $\$ 320$ en que pretende cogerse siete leguas de terreno de mi pueblo; cuando mi representado por segunda vez se preparaba á pedir la recisión de un contrato que no puede subsistir en buen derecho. No es cierto por último que autoridad alguna de mi pueblo haya mandado cometer los abusos de que el Señor Díaz se queja; y quiere justificar con los oficios que adjunta los cuales Conciudadano Jefe no significan mas que el descontento y la inconformidad de mi pue- 
blo, en verse despojar de sus tierras de una manera tan injusta é ilegal, ni conformidad mal expresada á causa de nuestra ignorancia, pero que tiende á evitar avances del acusante sobre tierras cuya propiedad se ventila en juicio

Santiago Xanica, Agosto 25 de 1890.

Por el Presidente Municipal

Valentín Lopez

Secretario

\section{Documentos Del SEgundo EXPEDIENTE}

Adjudicaciones y Conflictos, Miahuatlán, leg. 19, exp. 17, 1901

\section{Ciudadano Jefe Político}

Por acuerdo de la Corporación municipal que precido y en contestación á la respetable nota de $\mathrm{Vd}$. de 3 de este mes manifiesto: que el desistimiento del Síndico á que se alude en la Superior comunicación del Ministerio de Fomento, no fué autorizado por el Ayuntamiento de esta población, ni aprobado por el Superior Gobierno del Estado, por lo que no tiene eficacia, ni valor alguno, dadas las limitadas facultades que tiene un Síndico municipal, ascendencia del acto y que para cualesquiera actos ó contratos de los Ayuntamiento del Estado que se relacionan con sus bienes, es necesaria la aprobación de Gobierno, sin la que no son eficaces, como terminantemente lo dispone la de Ayuntamientos vigente.

Ese desistimiento podemos decir que fué inplantado, porque, si no se usaron otros medios reprobados para alcanzarlo, se abusó sin duda de la ignorancia del Síndico, caso de haberse firmado recogiendole sus firmas sin que entendiera, ni infiriera que documento firmaba.

No se esplica de otro modo ese intempestivo é inconcebible desistimiento, si se considera que el terreno denunciado es propiedad de los vecinos de este pueblo, y que es el único con que cuentan para sus siembras, para pastos de sus ganados y para otros usos que son indispensables para la vida del pueblo y de sus moradores.

Además, el Señor Juez de Distrito tiene admitida la oposición del actual Presidente y Síndico de este ayuntamiento á la expedición 
del título solicitado por el Señor Díaz y há declarado contencioso el asunto, motivo por el que creemos que entretanto no se resuelva esa contienda, no podrá expedir dicho título.

Alentar las razones expuestas, la justicia clara y manifiesta de nuestra causa y en consideración á los gravísimos e irreparables perjuicios que se causarían al vecindario de esta poblacion si el Señor Díaz se adjudicara los terrenos que pretende y procura adquirir de una manera tan injustificada, suplico á Vd. encarecidamente que rinda nuevo informe al Superior Gobierno del Estado, redactando ó transcribiendo este Oficio y esponiendo todo cuanto creyere justo y debido manifestar sobre el asunto, para que el mismo Superior Gobierno en defenza de la integridad del territorio del Estado y de los justos y legítimos derechos de este pueblo, de su vecindario y de la ranchería de Cuixtepec que está dispuesta á erogar los gastos que sean necesarios para su erección en pueblo, se sirva gestionar que no se expida el título ambicionado por el Señor Díaz, atendiendo ante todo á que no por el lucro ó beneficio de este señor ó por la insignificante cantidad que ofrece por extensos y fértiles terrenos, há de causarse la ruina de un pueblo y se han de perjudicar hondamente los intereses de la agricultura, entregando esos terrenos á un hombre inepto y codicioso que solo habrá de especular con ellos.

Reitero mi suplica y protesto á $\mathrm{Vd}$. mi consideración y respeto.

Libertad y Constitución

Santiago Xanica, Julio 11 de 1901

El Presidente M[unicipal]

$$
[\ldots]
$$

C. Gobernador del Estado

Francisco Parada, apoderado del Síndico Municipal de Santiago Xanica, como lo justifico con el poder que presento y pido se me devuelva, ante Ud. respetuosamente digo: que los Señores Pedro y Teófilo Díaz tiempo ha que pretenden adquirir los terrenos pertenecientes al expresado pueblo.

Primero procuraron tomarlos en arrendamiento para establecer una finca cafetera; despues lograron que se los vendiera comercial- 
mente el Municipio de Xanica por un ínfimo precio que pagarían en un largo plaz[o], y, por último, no habiendo pagado las rentas de arrendamiento, ni el precio de venta aludido, denunciaron ese terreno como baldío y pidieron en adjudicación por un título.

Para alcanzar este fin procuraron segun me informan los interesados, que el Síndico de Xanica se desistiera de la apresiacion que habia presentado contra el denuncio, para que terminara el juicio que habia surgido de esa oposición.

Acerca de ese decantado desistimiento importa advertir primero, que el Síndico nunca estuvo autorizado por el Ayuntamiento de Xanica para hacerlo; segundo, que aun supuesta esa autorizacion, sin la aprobacion del Gobierno, sería ineficaz y nulo porque importa la renuncia, del dominio y posesion de un bien raiz y los Ayuntamientos nada pueden hacer á este respecto sin el acuerdo del Gobierno, como terminantemente lo previene la Ley de Testamentos; tercero, su desistimiento fué calificado por un Síndico que no estaba en el ejercicio de sus funciones, que habia cesado en su empleo por la terminacion del plazo ó periodo legal de su nombramiento, y cuarto, de las mismas constancias de autos se desprende que se procuró que surtiera sus efectos ese desistimiento de modo que el Ayuntamiento no se apercibiera del suceso y no pudiera contar sus consecuencias. El juez del Distrito, por otra parte, no cuidó de recabar el consentimiento del Municipio, ni menos el de los que, segun los mismos Señores Díaz, aparecian como verdaderos interesados en el asunto.

Llama la atención que habiendo negado los Señores Díaz al Ayuntamiento de Xanica todo derecho y accion sobre dichos terrenos, asegurando que fueron de Santa María Cuixtepec y como nunca han sido de [Xanica] suplen sin embargo, el disistimiento del Síndico de ese ultimo pueblo y en el se prenden para adjudicarse los terrenos.

Hay antecedentes en la Secretaría del Gobierno sobre el asunto á que me refiero, motivados por la solicitud relativa a que se destinaran á la fundacion de un nuevo pueblo por los hijos del extinguido de Santa Maria Cuixtepec y por los informes que pidio el Secretario de Fomento acerca del mismo negocio. 
No es justo, ni debido que los Señores Díaz se adjudiquen una gran extencion de terrenos fértiles por una cantidad insignificante, despues que se han aprovechado de ellos sin pagar ninguna renta y despues que reconocieron primero y negaron al fin que Xanica fuera dueño de ese bien, conducta inexplicable y reprensible, que revela cuan distante de la verdad se encuentra cuanto han dicho y cuanto han hecho en su negocio

Los Señores Díaz no tienen ni capital ni elementos para explotar dichos terrenos, y los adminsitrarian tan solo para especular con ellos, con gravisimo perjuicio e irreparable daño de los vecinos de Xanica, que hace unos años la poseian, teniendo alli sus ranchos, sus ganados, sus siembras y sus plantaciones en considerable número y de mucha cuantía.

Juzgandose dueños los Señores Díaz de los repetidos terrenos, no obstante que hasta hoy no les ha expedido el título el Ministerio de Fomento, promovieron amparo contra el Presidente y Síndico de Xanica porque aseguraron que estos funcionarios habian repartido esos terrenos entre los vecinos de su pueblo. Ese juicio lo perdieron los expresados Señores porque el Tribunal no encontro justificados los hechos, ni que los pronunciantes fuesen dueños o poseedores de los terrenos.

Los mismos Señores para registrar la expedición del título pretendieron rendir una informacion testimonial ante el Juez de Distrito, se hizo saber esa solicitud al Síndico de Xanica y por la oposicion de ese funcionario el asunto se declaró contencioso el asunto, y de nuevo apelaron los Señores Díaz, perdiendo hoy el asunto ante el $3^{\circ}$ Tribunal de Circuito.

En vista de todo lo expuesto y haciendo uso el Ejecutivo de Estado de la facultad que le concede el artículo 29 de la ley vigente sobre ocupacion de terrenos baldios, a $\mathrm{Vd}$ suplico, que, previos los datos que fuere necesario acopiar, se sirva dirigirse á la Secretaria de Fomento para hacer las observaciones que estime convenientes a fin de impedir que se expida a los Señores Díaz el título de adjudicación que pretenden, amparando al pueblo de Xanica para que no sean privados de su propiedad y posesiones sus vecinos

Oaxaca, Septiembre diez de mil novecientos uno = Entre parénte- 
sis y subrayado $=$ Cuixtla $=$ el asunto No vale $=$ Entre líneas $=$ Xani $\mathrm{ca}=$ Vale

\author{
Francisco Parada
}

\title{
$[\ldots]$
}

Es vista Por mi su atenta nota oficial de fecha 28 del pasado en la que inserta la que la $1^{\text {a }}$ Sección de esa Secretaría dirigió al Ciudadano Gobernador pidiendole solicite informe de esta Jefatura sobre lo que ocurre entre los Señores Teófilo y Pedro Díaz y el Municipio de Xanica y Ranchería de Cuixtepec, con respecto á los terrenos denunciados por aquellos, la cual nota se sirvió remitirme para que informe sobre el particular; y en acatamiento á lo mandado paso á manifestar lo siguiente:

$1^{\circ}$ Que le pueblo de Xanica y su mancomunado Ranchería de Cuixtepec, sujetos antes á la jurisdicción del Distrito de Pochutla, acogieron de vecinos á los denunciantes, porque estos ofrecieron servir como tales y aún á influir con sus relaciones para que el pueblo se segregara del Distrito citado y se agregara á este.

$2^{\circ}$ Que acogidos los denunciantes como vecinos, con tal carácter entraron á ocupar parte del terreno conocido por de la $[s i c]$ comprensión de Cuixtepec y pusieron desde luego en dicha parte un plantío de café que aún existe en la actualidad.

$3^{\circ}$ Que posesionados los denunciantes de la parte del terreno arriba indicado, se procuraron una escritura de él; al efecto, aprovechándose de la ignorancia de los miembros del Municipio, hicieron aparecer en este de Secretario, á un individuo del origen de ellos (Sitio de Xitlapehua) y este empleado por el Presidente y Síndico que no sabían escribir, que no es otra más que la de renta de parte del terreno por la cantidad de $\$ 200$. Pagados al vencimiento de diez años, con obligación los compradores de pagar los réditos á razón de $6 \mathrm{p}$ oo anualmente no redimiesen aquella cantidad.

$4^{\circ}$ Que apollados los denunciantes en la escritura aludida, quisieron después de algunos años que el municipio recibiera los réditos que se habían vencido y como aquel rehusó el recibirlos los denunciantes se pusieron en silencio. 
$5^{\circ}$ Que vencidos los diez años término fijado en la escritura relacionada, los denunciantes ofrecieron pagar los $\$ 200.00$ del terreno y los reditos correspondientes; pero el municipio se opuso y por la oposición, los denunciantes abandonando el juicio que habían promovido sobre consignación de pago, se lanzaron á denunciar como baldío, no solo la parte del terreno que se les había permitido ocupar como vecinos y del cual hubieron de arbitrarse la escritura de que queda hecha referencia, sino todo el conocido por de la $[s i c]$ comprensión de Cuixtepec y aún parte del pueblo de Xanica.

$6^{\circ}$ Que hecho el denuncio, los denunciantes, para venir á la adjudicación del terreno que pretenden, han usado de medios hasta ilegales como son de afirmar que el terreno es baldío, que el terreno todo está y ha estado ocupado por ellos, que ningunos otros lo poseían ni han poseido y que de la oposición que el Municipio había venido haciendo para la adjudicación se había desistido ya cuando todo esto no es cierto.

Hasta aquí reseña de lo que ha ocurrido entre los denunciantes y el Municipio de Xanica y su mancomunado Ranchería de Cuixtepec, con respecto al terreno denunciado; ahora, por lo que toca á estos, así como á la posibilidad en que se encuentran los moradores de dicha Ranchería para que la agrupación de ellos se erija en pueblo y conveniencia que hay en esto, reasumo mi informe diciendo por conclusión del I Que el terreno denunciado no es baldío sino de comunidad. II Que el terreno denunciado solo está ocupado en una muy pequeña parte por los denunciantes y que además de él, en extensión como de kilómetros, lo está y ha estado desde tiempo memorial por vecinos de la Ranchería de Cuixtepec y de Xanica pues tienen diseminados en aquella sus ranchos, sus plantaciones agrícolas y sus ganados y son en tanto número que pidieron ya la erección en pueblo, cuya petición está pendiente de resolución en el Congreso del Estado.- III. Que Xanica no se há desistido ni desiste de la oposición á la adjudicación, por que aún cuando los denunciantes han aducido como prueba de ello un documento que así parece ó lo dá á entender, tal desistimiento ási concertado carece de la aprobación del Superior Gobierno, requisito indispensable según la fracción XI del artículo 19 de la Ley de Ayuntamientos. IV Que 
los moradores de la Ranchería de Cuixtepec están en posibles para la construcción de casas municipales y para el desempeño de los cargos públicos; ya por que son en número de más de doscientos, como por que cuentan con los elementos de su [...] que son consiguientes en climas tropicales como el en que [sic] moran y V. Que conviene se erija en pueblo dicha Ranchería, porque solo así podrían los Jefes de familia de aquella agrupación conseguir el que se establesca en el lugar donde moran una Escuela para la instrucción de sus hijos.

Como consecuencia de todo lo expuesto, me parece de justicia que no se acceda á la adjudicación del terreno á que se refieren los denunciantes y sí que se erija en él, el pueblo pedido por los de la Ranchería de Cuixtepec, señalandose para este lo que corresponde según la ley para el fundo legal y repartiendo lo demás del terreno entre los Jefes de familia de aquella, respetando siempre la parte que ocupan los Señores Díaz. Tal es mi parecer, salvo lo que la Superioridad tenga por conveniente acordar en definitiva sobre lo que se trata.

Con lo expuesto, dejo emitido el informe y parecer que se me pidio y obsequiado por consiguiente lo mandado en la citada nota que contesto con todo respeto.

Libertad y Constitución

Miahuatlán, Octubre 9 de 1901

El Jefe Político

Feliciano García

M C. S[ecreta]rio g[ene] ral del Despacho del Superior Gobierno del Estado

$$
[\ldots]
$$

\section{Gobernador}

Con motivo del remiso presentado á esa Superioridad por el Síndico Municipal del pueblo de Xanica, Distrito de Miahuatlán, solicitando que el Gobierno haga las observaciones que estime justas á la Secretaría de Fomento, en el expediente que sobre adjudicación de terrenos baldíos tienen promovido los Señores Pedro y Teófilo Díaz 
ante la mencionada Secretaría, se pidió al Jefe político de Miahuatlán un informe circunstanciado para mejor conocer los antecedentes de este asunto y habiéndose rendido ya, la Secretaría de mi cargo se permitió referir en breves términos los antecedentes que del relacionado informe se desprenden:

$1^{\circ}$ Que los Señores Pedro y Teófilo Díaz se avecindaron en el pueblo de Xanica y acogidos como vecinos por el pueblo, entraron á rentar parte de los terrenos de la composición de la Ranchería de Cuixtepec. Aprovechándose de la ignorancia de los miembros del Municipio, formularon una escritura de los propios terrenos, autorizándola con su firma un individuo extraño á la Corporación, á quien se dio el carácter de Secretario, en virtud de no saber escribir el Presidente y Síndico Municipales de Xanica: De conformidad con tal escritura, los $S$ [eñores] Díaz compraban el terreno en la cantidad de $\$ 200.00$, pagaderos en el término de diez años y con la obligación los compradores de pagar por censos un 6\% anual en tanto no redimieran el capital de $\$ 200.00$. Cuando los interesados lo juzgaron oportuno, ocurrieron al municipio en virtud de que se les recibieran los réditos de varios años, á cuya pretensión se opuso la Corporación. Vencido el plazo de los diez años, los mismos interesados ofrecieron redimir los $\$ 200.00$ y pagar los réditos vencidos, pero como encontraron oposición por parte del Ayuntamiento, se reservaron á denunciar, como lo han hecho, los terrenos aludidos en el carácter de baldíos, en cuyo denuncio abarcaron mayor extensión de terrenos de la Ranchería de Cuixtepec y aun parte de los de Xanica, que no poseían.

$2^{\circ}$ Que los terrenos en cuestión, en su mayor parte están y han sido ocupados desde tiempo memorial por los naturales de Cuixtepec y Xanica, y en ellos tienen establecidas sus plantaciones y sus ganados; $y$

$3^{\circ}$ Que la Ranchería de Cuixtepec ha solicitado del H. Congreso del Estado su erección como pueblo, por cuyo efecto cuenta con los elementos necesarios.

En tal virtud, el Jefe que suscribe es de parecer, salvo el más acertado de Ud., que se transcriban á la Secretaría de Fomento el ocurso é informe relacionados, haciendo suyo este Gobierno el informe ren- 
dido por el Jefe p[olítico] de Miahuatlán, á fin de que la expresada Secretaría se sirva tomar en consideración lo expresado en ambos documentos, al resolver sobre la solicitud de los [Señores] Díaz.

Oaxaca de J[uárez], Noviembre 41901

Enrique León

\section{$[\ldots]$}

Con esta fecha se dice por esta Secretaría al Juez de Distrito de ese Estado: Del estudio que se ha hecho nuevamente en esta Secretaría del expediente instruido ante ese juzgado con motivo del denuncio que formularon los C.C. Pedro y Teófilo Díaz del terreno baldío llamado "La Sirena", sito en la jurisdicción del Distrito de Miahuatlán, de ese Estado, aparece que no hubo citación de colindantes, pues aun cuando el Juez de Distrito en su auto de 15 de Mayo de 1893 dispuso que los colindantes fueran citados por medio de los edictos que se publicaron por tres veces en el periodo oficial, debiendo propiciar la mensura diez días despues de la última publicación (9 de junio de 1893); sin embargo dichas operaciones no comenzaron sino transcurrido un ańo el 16 de julio de 1894, sin que á los colindantes como interesados se les hubiera notificado esa dilación, así es que la mensura se practicó sin que hubieran comparecido todos los colindantes por no haberlos citado oportunamente $=$ Consta así mismo que corridos los demás trámites del denuncio, se decretó la adjudicación de las cuatro mil setecientas cincuenta y (cuatro) treinta y dos aras, veinticuatro centiaras que arrojó la mensura del expresado baldío en común a los dos denunciantes, sin haberse dado cumplimiento a lo prevenido en el Decreto de 27 de Diciembre de 1872 que terminantemente previene que en esos casos como el de que se trata, se decretará la adjudicación previo señalamiento en el terreno y en el plano de la parte que á cada uno corresponde y que eludiendo dicho requisito Teófilo Díaz cedió á favor de su hermano Pedro sus derechos cuya cesión fué aceptada por el juez, convirtiéndose así Pedro Díaz en adjudicatario de la totalidad del terreno, en abierta contraposeción con el art. $2^{\circ}$ de la Ley de 20 de Julio de 1863. En vista pues, de lo expuesto y en uso de la facultad que le concede el 
art. 18 de la citada Ley de 20 de Julio de 1863, el C. Presidente de la República ha tenido á bien disponer que no es de aprobarse como en efecto no se aprueba el auto, de ese Juzgado de fecha 23 de Enero de 1893. = Lo que comunico á V. para su conocimiento y á efecto de que se sirva decretar la declaración correspondiente.

Lo que me honro en insertar á $V$. para su conocimiento en relación á su atento oficio del 6 de Noviembre del año próximo pasado.

Libertady Constitución. México, Julio 5 de 1902.

C.C: Gobernador del Estado de Oaxaca.Notas 